\title{
Methanization of Fossil Fuel: A Possible Sustainable Future Energy Source for Mankind?
}

\section{Phil M. Oger*}

Laboratoir dè Geologiè de Lyon, CNRS UMR 5276, Univusitè de of Lyon, ENS Lyon, 46 Allée d'Italie, Lyon, France

One of the main human challenges over the ages has been to find and exploit the best and most efficient source of energy. Mastering of wood, coal, petroleum and nuclear powers have marked out the path to progress. Today, petroleum and coal represent the most extensively used energy source worldwide and the resources tend to be depleted. The large scale burning of fossil fuels also comes at a high environmental cost and we are still trying to imagine the next generation energy source. It is not expected that renewable energies based on the harvest of solar or wind energy will supplant fossil fuels in the near future. Thus, we are stranded with fossil fuels for at least the next few decades and need to find ways to make our use of fossil fuels cause the least environmental impact. One approach to reducing the environmental impact of fossil fuel usage is to lower $\mathrm{CO}_{2}$ emission per $\mathrm{Kj}$ of energy, a claimed advantage of biogenic methane. Thus, in time of declining discovery of conventional fossil fuel reserves and the ongoing issues relating to security of energy supply and global warming methane may represent the future for fossil fuels.

Fossil fuels, e.g. oil and coal, are mainly composed of hydrocarbons, whether linear, cyclic or chained, that originates from the geochemical and microbiological transformation of buried macromolecular organic matter. Hydrocarbons are non polar and have low aqueous solubilities. Accordingly, they are some of the most reduced and chemically inert organic compounds in natural ecosystems. Saturated hydrocarbons, $\mathrm{n}$-alkanes and isoprenoids, are the most abundant compound in petroleum, which also contains a substantial fraction of low molecular weight aromatic compounds such as benzene, toluene, ethylbenzene or xylene and low molecular weight polyaromatic compounds (PAHs) such as napthalenes, phenanthrenes, or biphenyls. Comparatively, coal contains a heavier proportion of insoluble polycyclic compounds. Hydrocarbons are distributed ubiquitously from surface environments through the shallow subsurface to the deep subsurface. Methane is often present in these carbon rich environments. It has long been considered a by-product of the evolution of coal and oils under the high temperature and pressure needed for their maturation. In recent years, it has become obvious from carbon isotopic data that in many settings biogenic methane represented from a significant fraction to the majority of the gas present in the reservoirs [1]. With evidence for microbial oil- or coal-derived methane generation accumulating, one can ascertain today that any coal bed or petroleum reservoir at temperatures less than $80^{\circ} \mathrm{C}$ contains microbial communities capable of generating biogenic methane, a process called methanogenesis. Questions about whether methanogenesis is active and/or significant in situ today is still under question.

Methanogenesis is the formation of methane by microbes known as methanogens. All methanogens known to date belong to the domain Archaea. Methanogens use carbon as a terminal electron acceptor. Carbon can occur only in a very small number of organic compounds, all with low molecular weights, with 1 or two carbons at best. The two best described pathways involve the use of carbon dioxide and acetic acid. The production of methane is an important and widespread form of microbial metabolism. In most environments, it is the final step in the decomposition of biomass. In absence of electron acceptors other than carbon, low molecular weight carbons suitable for methanogen respiration originate from the fermentation of the biomass by consortia of different bacterial species, which rely on methanogens for the removal of fermentation by products such as hydrogen and $\mathrm{CO}_{2}$. Anaerobic fermentation/methanogenesis is the archetypic example of a syntrophic relationship between different groups of microorganisms. Although the fermenters are not strictly dependent on the syntrophic relationship, they gain profit from the scavenging of hydrogen by methanogens, since they gain maximum energy yield when protons are used as electron acceptor with concurrent $\mathrm{H}_{2}$ production. Methanogenesis is beneficially exploited to treat organic waste in biogas fermentors and the methane produced is collected and used as biogas.

Although evidence for aerobic hydrocarbon-degradation have been known for nearly a century, and the enzymes and mechanisms they employ are well understood, it is only very recently that evidence for strictly anaerobic degradation of hydrocarbons were obtained and the first consortia of syntrophic bacteria and methanogenic archaea could be described [2]. Besides the presence of methane, which origin could be debated, direct evidence for anaerobic hydrocarbon degradation comes from the detection of intermediate metabolites that are present in reservoir-degraded oils from around the world, but not present in "pristine" or aerobically degraded oils $[3,4]$. However, we still know little of the mechanisms employed by these anaerobes to overcome the chemically inert nature of hydrocarbons. Ecological studies have identified the systematic presence of Clostridia, Thermotoga, Bacteroidetes and other obligate fermenters suggestive of a fermentative capacity within the microbial community. In the absence of exogenous electron acceptors, methanogenesis is thought to play an important part in the degradation of hydrocarbon. Methanogenic incubations with coal or oil as a sole carbon source have been performed $[5,6]$. Studies show that growth rates of methanogenic hydrocarbondegrading communities in the laboratory are slow. However, a large range of hydrocarbons can be fully degraded to $\mathrm{CH}_{4}$ when inoculated with production waters from oil well or formation waters from coal seams. Methanogenesis rates in the laboratory can be increased by substrate amendment [1,7-9]. There is today ample evidence that methanogenesis also occurs in situ in deep and shallow petroleum reservoirs [8], as well as coal beds [10]. Conversion rates to methane in situ are extremely slow [11], rendering the exploitation of biogenic

*Corresponding author: Phil M. Oger, Ph.D, Laboratory of Geology of Lyon, CNRS UMR 5276, University of Lyon, ENS Lyon, 46 Allée d'Italie, Lyon, France, E-mail: philippe.oger@ens-lyon.fr

Received April 19, 2012; Accepted April 20, 2012; Published April 23, 2012

Citation: Oger PM (2012) Methanization of Fossil Fuel: A Possible Sustainable Future Energy Source for Mankind? Ferment Technol 1:e110. doi:10.4172/2167 7972.1000 e110

Copyright: (C) 2012 Oger PM. This is an open-access article distributed under the terms of the Creative Commons Attribution License, which permits unrestricted use, distribution, and reproduction in any medium, provided the original author and source are credited. 
Citation: Oger PM (2012) Methanization of Fossil Fuel: A Possible Sustainable Future Energy Source for Mankind? Ferment Technol 1:e110. doi:10.4172/2167-7972.1000e110

Page 2 of 2

gas possible only because of the geologic time-long accumulation of gas in the reservoirs. Less mature coal, lighter oil, and immature kerogen are the preferred substrate for the syntrophic-methanogenic consortia.

The wide distribution of methanogens in both shallow and deepsubsurface environments offers the potential to harness methanogenesis to transform unexploited or unexploitable petroleum reservoirs or coal beds into methane at an economic scale. In situ microbial conversion of residual oil, which is typically more than $50 \%$ of an oil field potential, to methane would allow the recovery of large amounts of energy [12]. It can also help transform inaccessible coal beds and immature source rocks to exploitable methane resources [13]. However, technological challenges must be overcome before biogenic methane from source rocks can make a serious contribution to global energy supply. One challenge is the engineering of the subsurface environments to effectively stimulate methanogenic consortia and recover the gas produced. The engineering challenges include the logistics of moving fluids, gases, and biostimulants through heterogeneous reservoir systems and the development of tools to monitor the process in situ. The key microbiological challenge is the stimulation of the indigenous or the establishment of an exogenous hydrocarbon-degrading microbial consortium within the target rocks. Energy recovery from proven biologically active target rocks would best rely on accelerating the natural methanogenic biodegradation rates. Several laboratories have shown that methanogenesis could be increased substantially in the laboratory by the addition of nutrients, demonstrating that bioaugmentation could be an important strategy for implementing enhanced in situ methanogenesis in source rocks. Tested nutrient additions included hydrogen, $\mathrm{CO}_{2}$, ammonia, phosphate, yeast extract, tryptone, milk, agar, trace metals, and vitamins, or inorganic nutrients. In addition to chemical stimulation of microbial conversion of coal to methane, some authors have suggested and experimented with the addition of selected microbial consortia. Examples of consortia used for methanogenic inoculation with coal in laboratory settings include a cultivated consortium indigenous to studied coal, a consortium obtained from termite guts, and a consortium obtained from an abandoned coal mine used as sewage disposal. However, this approach has some clear technical challenges. The first is linked to the logistics of producing an inoculum in sufficient amounts for the target system. The second is linked to the survival of the syntrophic methanogenic consortium during injection. It is a well known fact that the syntrophic partnerships between fermenters and methanogens is a physical association that small perturbation may disrupt [14]. The last challenge relies with the in situ survival of the methanogenic consortium in the target system, its ability to displace the indigenous flora and establish itself in situ. Very few such microbial introductions have been successful thus far, regardless of their target. Thus this may be the main challenge facing this approach.

The path to in situ methane transformation of coal or petroleum is still long. Several challenges remain before this approach can be economically sound. First it is essential that we become able to determine what fraction of the resource can be ultimately converted to methane, and therefore determine the influence of the geologic context, exploitation history and the microbiology in situ on the rate of methanogenesis that can be expected. Second, in order to improve and control its rates, we need to understand the initial steps of the fermentation process that generate the substrates for the methanogens. Coupled approaches of analytical chemistry and omics will help shed light on these rate-limiting initial steps. Third, as in many industrial processes, we need to understand how to best scale our cubic centimeter microcosms observations up to the scale of the cubic kilometer scale of the in situ reactor, that the petroleum reservoir or coal beds definitely are, before being able to aid field-scale microbial methane stimulation. Last, we need to evaluate whether the stimulated subsurface methane conversion rates using nutrients and specialized microbes will be enough to convert vast global fossil fuel reserves into economically fit gas resources. Despite the complexity and challenge, there is little doubt about the benefits of enhancing methanogenic hydrocarbon degradation in situ. Extrapolation of laboratory methane production data to a realistic field-scale application estimated a 3-13 billion cubic feet of methane per day for the sole known US oil reservoirs [7], e.g. ca $17 \%$ of current natural gas consumption in the United States.

\section{References}

1. Head IM, Jones DM, Larter SR (2003) Biological activity in the deep subsurface and the origin of heavy oil. Nature 426: 344-352.

2. Connan J (1984) Biodegradation of crude oils in reservoirs. In: "Advances in Petroleum Geochemistry". Brooks J, Welte DH (Eds), Academic Press, London, 299-330.

3. Aitken CM, Jones DM, Larter SR (2004) Anaerobic hydrocarbon biodegradation in deep subsurface oil reservoirs. Nature 431: 291-294.

4. Orem WH, Voytek MA, Jones EJ, Lerch HE, Bates AL (2010) Organic intermediates in the anaerobic biodegradation of coal to methane under laboratory conditions. Org Geochem 41: 997-1000.

5. Shumkov S, Terekhova S, Laurinavichius K (1999) Effect of enclosing rocks and aeration on methanogenesis from coals. Appl Microbiol Biotechnol 52: 99103.

6. Green MS, Flanegan KC, Gilcrease PC (2008) Characterization of a methanogenic consortium enriched from a coalbed methane well in the Powder River Basin, USA. Int J Coal Geol 76: 34-45.

7. Gieg LM, Duncan KE, Suflita JM (2008) Bioenergy production via microbial conversion of residual oil to natural gas. Appl Environ Microbiol 74: 3022-3029.

8. Jones DM, Head IM, Gray ND, Adams JJ, Rowan AK, et al. (2008) Crude-oi biodegradation via methanogenesis in subsurface petroleum reservoirs. Nature 451: 176-180.

9. Parkes J (1999) Cracking anaerobic bacteria. Nature 401: 217-218.

10. Jones EJP, Voytek MA, Warwick PD, Corum MD, Cohn A, et al. (2008) Bioassay for estimating the biogenic-generating potential of coal samples. Int J Coal Geol 76: 138-150.

11. Schlegel ME, Zhou Z, McIntosh JC, Ballentine CJ, Person MA (2011) Constraining the timing of microbial methane generation in an organic-rich shale using noble gases, Illinois Basin, USA. Chem Geology 287: 27-40.

12. Grigoryan A, Voordouw G (2008) Microbiology to help solve our energy needs: methanogenesis from oil and the impact of nitrate on the oil-field sulfur cycle. Ann N Y Acad Sci 1125: 345-352.

13. Strapoc D, Picardal FW, Turich C, Schaperdoth I, Macalady JL, et al. (2008) Methane-producing microbial community in a coal bed of the Illinois basin. Appl Environ Microbiol 74: 2424-2432.

14. Hatamoto M, Imachi $\mathrm{H}$, Ohashi A, Harada $\mathrm{H}$ (2007) Identification and cultivation of anaerobic, syntrophic long-chain fatty acid-degrading microbes from mesophilic and thermophilic methanogenic sludges. Appl Environ Microbiol 73: 1332-1340. 